Highlights (van Strien et al.):

- Mediation analyses addressed relations between eating, palatability and mood

- In non-obese women, eating tasty snacks improved mood after sadness induction

- Mood improvement after eating was mediated by eating satisfaction

- For eating after stress, tastiness mediated comfort only for high emotional eaters

- This clarifies that eating palatable food is comforting for emotional eaters 


\section{Is comfort food actually comforting for emotional eaters? A (moderated) mediation \\ 2 analysis}

3

4 van Strien, Tatjana ${ }^{\mathrm{a}, \mathrm{b}}$, Gibson, E. Leigh $^{\mathrm{c},}$, Baños, Rosa ${ }^{\mathrm{d}, \mathrm{e}}$, Cebolla, Ausiàs $^{\mathrm{d}, \mathrm{e}}$ and Winkens, 5 Laura H.H. ${ }^{\mathrm{f}}$

6

7 a. Behavioural Science Institute, Radboud University, The Netherlands

8

b. Faculty of Earth and Life Sciences, Institute of Health Sciences, Vrije Universiteit

9 Amsterdam, The Netherlands

c. Department of Psychology, Whitelands College, University of Roehampton, London, UK

d. CIBER Fisiopatología Obesidad y Nutrición (CIBERObn), Instituto Salud Carlos III, Spain.

e. Department of Personality, Evaluation and Psychological Treatment, University of Valencia, Spain.

f. Consumption and Healthy Lifestyles Chair group, Wageningen University \& Research, Wageningen, the Netherlands.

19 Corresponding author: Tatjana van Strien. Postal address: PoBox 9102, 6500 HC Nijmegen, 20 the Netherlands. E-mail: t.vanstrien@psych.ru.nl 
22

23

24

25

26

Abstract

An important but unreplicated earlier finding on comfort eating was that the association between food intake and immediate mood improvement appeared to be mediated by the palatability of the food, and that this effect was more pronounced for high than for low emotional eaters (Macht and Mueller, 2007a). This has not yet been formally tested using mediation and moderated mediation analysis. We conducted these analyses using data from two experiments on non-obese female students ( $n=29$ and $n=74)$. Mood and eating satisfaction in Study 1, and mood, tastiness and emotional eating in Study 2 were all selfreported. In Study 1, using a sad mood induction procedure, emotional eaters ate more food, and when mood was assessed immediately after food intake, 'eating satisfaction' acted as mediator between food intake and mood improvement (decrease in sadness or increase in happiness). In Study 2, where we measured the difference in actual food intake after a control or a stress task (modified Trier Social Stress Test), and assessed mood during the food intake after stress, we found significant moderated mediation. As expected, there was a significant positive mediation effect of tastiness between food intake and mood improvement in the high emotional eaters, but also a significant negative mediation effect of tastiness between food intake and mood improvement in the low emotional eaters. This suggests that tastiness promotes 'comfort' from food in female emotional eaters, but conflicts in non-emotional eaters with a tendency to eat less when stressed. In conclusion, palatable food may indeed provide comfort specifically for high emotional eaters during eating.

Keywords: Food, mood, emotional eating; tastiness; eating satisfaction. 
47 1. Background

48 The typical adaptive response to negative mood or distress is loss of appetite (Gold \&

49 Chrousos, 2002), because distress is normally associated with physiological responses that 50 mimic physiological correlates of satiety, e.g. inhibition of gastric motility and release of

51 glucose into the bloodstream. However, so called emotional eaters show the atypical response 52 to distress of eating energy-dense food, and thus additional calories (Oliver, Wardle \& 53 Gibson, 2000; Van Strien, Herman, Anschutz, Engels \& de Weerth, 2012; van Strien \& 54 Ouwens, 2003; Wallis \& Hetherington, 2004), which may result in weight gain and, ultimately, obesity (Gibson, 2012; Koenders \& van Strien, 2011). According to psychosomatic theory as advocated by Bruch (1973), this atypical stress response of emotional eating is learned in early childhood when the child is fed in response to emotional rather than to hunger cues. The child then gradually "learns" to eat in response to negative emotions as an anxiety reducing mechanism (Slochower \& Kaplan, 1980). Though emotional eating is perceived to be an emotion regulation strategy (Macht $\&$ Simons, 2000), there is as yet no conclusive experimental evidence that emotional eating indeed helps to reduce negative emotions, so-called "affect reduction", with any efficacy (Macht \& Mueller, 2007a). Ecological momentary assessment (EMA) research on the affect regulation model of binge eating, a type of overeating that, similar to emotional eating, is preceded by negative emotions, showed contradictory findings depending on differences in statistical approaches (Berg et al., 2017). When studying the trajectory of the mood before and after an eating binge over time, mood tended to improve over time after a binge (e.g., Berg et al., 2015). When assessing the difference in negative affect right before and right after an eating binge, mood showed a deterioration right after the eating binge (e.g., Hilbert \& Tuschen-Caffier, 2007; Stein et al., 2007; Wegner et al., 2002). An advantage of EMA, where the variables of interest 
72 the ecological validity of the data. However, as pointed out by Haedt-Matt \& Keel (2011), a

73 key problem of EMA, apart from its possible reactivity (Stone \& Shiffman, 1994), is that it does not permit causal conclusions, for example that the mood improvement in the study by Berg et al., (2015) was caused by the eating binge, as it could also, simply, be explained by the passage of time.

Furthermore, experiments in (predominantly) women with obesity, binge eating disorder or loss of control over eating showed mixed evidence in regard to the mood improving effects of food intake after negative emotions (e.g., Agras \& Telch, 1998; Ranzenhofer et al., 2013). In the study by Agras and Telch (1978) on women with binge eating disorder, negative mood after a mood induction (negative vivid imagery) was significantly reduced after food intake, but the study design did not permit disentangling whether this reduction in distress was due to the intake of food or, simply, the passage of time. In their study on adolescent girls with loss of control over eating, Ranzenhofer et al. (2013) similarly found that the (non-manipulated) negative mood was significantly reduced from pre- to post-meal, but here there was no significant association between the decrease in negative mood and the amount of food eaten. Using EMA, a similar observation was made by Goldschmidt et al. (2012) in their subgroup of persons who combined obesity with binge eating disorder: the post-meal reduction in negative affect was found to be unrelated to the amount of food consumed. Only in the subgroup of individuals with obesity but without binge eating disorder was there a significant association between the post-meal reduction in negative affect and the amount of food eaten (Goldschmidt et al., 2012).

In addition to the palatability of the food offered (Macht \& Mueller, 2007a), the timing of the measurement of negative affect may also play a role (Daever et al., 2003). In the study by Daever et al. (2003), one of the few EMA studies where participants (women with binge eating) rated their mood throughout the course of a binge meal, there was only an 
improvement in mood during, but not following the binge meal. In the same line, Macht and Mueller (2007a) found in experiments on men and women that eating chocolate reduced negative mood (induced by a sad film clip), but that this effect only had a short duration and was no longer present after three minutes. A further interesting finding in that same study was that eating palatable chocolate (milk chocolate) improved the negative mood more than eating the unpalatable chocolate (dark chocolate) or no food, and that the palatable chocolateinduced mood improvement was associated with emotional eating. The mood elevation immediately after eating the palatable chocolate was more pronounced in the high than in the low emotional eaters (as determined by a median split of the emotional eating scale of the DEBQ (Dutch Eating Behaviour Questionnaire; van Strien, Frijters, Bergers \& Defares, 1986): "This difference disappeared 2 min after eating...., but was manifest again 3 min after eating" (Macht \& Mueller, 2007a, p. 672).

The findings by Macht and Mueller (2007a) were taken as the starting point for the present two studies. The importance of the palatability of the test food for mood improvement in the study by Macht and Mueller (2007a) suggests that the palatability of the test food may act as a mediator between food intake and mood improvement. This is supported by the finding that experimentally induced stress elicited greater intake specifically of sweet fatty foods, which were the most liked, from a buffet lunch in emotional eaters, not of lunch intake overall (Oliver et al., 2000). However, palatability is not a fixed facet, and the degree to which a particular food is perceived as tasty or pleasant may differ across individuals (Wagner, Ahlstrom. Redden, Vickers \& Mann, 2014), and can be context-dependent (Booth, 1990), with, for example, restrained eaters rating the plain chocolate ( $70 \%$ and $85 \%$ cocoa) as more pleasant (Macht \& Mueller, 2007b), and men preferring savoury over sweet foods (Wansink, Cheney \& Chan, 2003). Therefore, it is perhaps the experienced palatability, pleasantness or taste of the food offered that acts as a mediator between the food intake and mood 
improvement. Further, the moderator effect of emotional eating in the studies by Macht and Mueller (2007a) and of Oliver et al. (2000) suggest that this mediation effect may be contingent on emotional eating status, with stronger mediation effects of experienced good taste or palatability likely for high than for low emotional eaters.

We tested these possible mediation and moderated mediation effects by re-analyzing data from two earlier studies on food intake after a mood induction in high versus low emotional eaters where we found a significant improvement of mood during or after the food intake after a negative mood induction (Van Strien, Herman, Anschutz, Engels \& de Weerth, 2012; Van Strien et al., 2013). Both studies included only females, because of the greater prevalence of stress-induced food intake in females (O’Connor, Jones, Conner, McMillan and Ferguson, 2008). In Study 1, we assessed the mediation effect of experienced pleasantness ('eating satisfaction') between food intake and mood improvement after the food intake. In Study 2, we investigated whether a mediation effect of experienced palatability is contingent on emotional status, predicting stronger positive mediation effects for high than for intermediate or low emotional eaters.

\section{Study 1}

\subsection{Overview of Study 1}

In this study we wanted to determine whether experienced pleasantness acts as a mediator between food intake and mood improvement. The pleasantness of the food intake was assessed with a concept that covers the hedonic experience of eating, namely 'eating satisfaction' (Andersen \& Hylding, 2015), i.e. more precisely representing the pleasantness of the overall intake experience rather than a more general palatability of the food. Because the study used a between-subject design, with half of the participants receiving a happy and the 
other half a sad mood induction (Van Strien et al., 2013), only the data from the participants

147 in the sad mood condition could be used for the present study.

148 Earlier, we found with the entire dataset that self-reported emotional eating status significantly moderated the relation between the mood condition and snack intake (van Strien, Cebolla, et al., 2013): high emotional eaters ate significantly more after the sad than after the happy condition. A further finding was that the sad mood induction was associated with a significant increase in sadness compared to pre-test, but that sadness was significantly reduced after the food intake (see Figure 2 in van Strien, Cebolla et al., 2013). Similarly, the sad mood induction was associated with a significant decrease in happiness compared to pretest (Figure 3 in van Strien, Cebolla et al., 2013), but after food intake, happiness was significantly increased. However, whether eating satisfaction acts as a mediator between food intake and any decrease in sadness, or conversely increase in happiness, has not yet been determined with the data in the sad mood condition.

\subsection{Method}

\subsubsection{Participants}

This is a new analysis of existing data from female participants in a virtual reality mood induction experiment who had been recruited from a pool of students taking courses at the Universities of Valencia and Barcelona (Spain) and who had completed in class the Spanish (Castilian) version of the Emotional Eating scale of the Dutch Eating Behaviour Questionnaire (DEBQ), (Cebolla, Barrada, Van Strien, Oliver \& Baños, 2014). Students with emotional eating scores below or equal to 1.8 , or above 2.6 , had been invited by phone to participate in the study. Details on the exclusion criteria and the design and the procedure of the experiment can be found in van Strien, Cebolla et al. (2013). 
171 Participants in the present study were 29 women (15 low and 14 high emotional

172 eaters), who had been subjected to the sad mood induction, a virtual reality (VR-MIP) system

173 situated in an urban park, with music and movie scenes (an excerpt of the movie "The

174 Champ") designed to induce sadness. The women had a mean BMI of $22.32(\mathrm{SD}=3.35) \mathrm{kg} / \mathrm{m}^{2}$

175 and a mean age of $24(\mathrm{SD}=6)$ years. The study protocol was approved by the ethics board of

176 the University of Valencia, and all participants gave signed informed consent.

177

$178 \quad$ 2.2.2. Procedure

179 Participants were instructed to refrain from food intake for at least $2 \mathrm{~h}$ prior to arrival.

180 Experimental sessions were scheduled well before lunch or dinner. After the mood induction

181 procedure using the VR-MIP system (for details, see van Strien, Cebolla et al., 2013) (30 min)

182 the participants were taken to a separate room with a choice of various foods on individual

183 plates, providing a range of sweet, salty, or savoury high- or low-fat foods: apple, banana,

184 salty peanuts, sweet peanuts, chips, jelly sweets, cereal bar, chocolate, rice diet bar and

185 rosquilleta (Valencian toasted salty bread). Participants were left alone for 5 min to eat as

186 much from the food as they wanted (see van Strien, Cebolla et al., 2013 for details).

187

$188 \quad 2.2 .3$. Measures

189 Happiness and sadness: these emotions were measured with a 7-point visual analogue scale 190 (VAS; Gross \& Levinson, 1995) with responses to the question "How happy/sad do you feel 191 at the moment" ranging from 1 'not at all' to 7 'totally true' at three time-points: upon arrival 192 (T1), immediately after the mood induction (T2) and immediately after the food intake (T3).

193 Food intake: Before and after the participants ate, the individual plates with food were

194 weighed with a professional scale. We then translated weight into energy (kcal) for each food 195 type and summed the caloric intake over all types of food. 
196 Level of satisfaction: satisfaction with what was eaten ('eating satisfaction') was measured 197 immediately after the food intake (but after the assessment of happiness and sadness at T3)

198 with one question: How satisfied are you with what you have eaten? (Spanish: ¿Cómo de 199 satisfecho estás respecto a lo que has comido?). This question had a 6-choice response format 200 ranging from $1=$ 'not at all' to $6=$ 'totally'.

201 Guilty: feeling guilty after eating was measured immediately after the food intake and eating 202 satisfaction question (but also after the assessment of happiness and sadness at T3) with one 203 question: How guilty do you feel about what you have eaten? (Spanish: ¿Cómo de culpable te 204 has sentido por lo que has comido?). This question had a 6-choice response format ranging 205 from $1=$ 'not at all' to $6=$ 'totally'.

\subsubsection{Data analysis}

208 With repeated measures GLM we assessed the effects of the mood induction and food intake 209 on the values for sadness and happiness in the sad mood induction condition. Mediation of 210 eating satisfaction was assessed with model 4 of the PROCESS macro of SPSS version 23.0, 211 developed by Hayes (2013). We used bootstrapping with 5,000 samples. We conducted 212 separate analyses for change in sadness and change in happiness (Y): change in sadness and 213 change in happiness were calculated by assessing respectively, T3 sadness and T3 happiness, 214 and using respectively, T2 sadness and T2 happiness as covariates. It should be noted that 215 decrease in sadness is reflected by a negative score, whereas increase in happiness is reflected 216 by a positive score. In both cases, the independent variable (X) was food energy intake (kcal) 217 and the mediator (M) was eating satisfaction. In additional analysis we controlled for 218 sadness/happiness at baseline (Mood-pre), as well as 'guilt' (because of the possible 219 suppressing effect of guilt on eating satisfaction). 


\subsection{Results}

222

223 $233=.74)$.

\subsubsection{Manipulation check}

The mean (SD) of the sad mood values upon arrival (T1), immediately after the mood induction (T2) and after the food intake (T3) were, respectively, $1.55(.87), 4.66(.94)$ and 2.41 (1.09). The mean (SD) of the happiness mood values upon arrival (T1), immediately after the mood induction (T2) and after the food intake (T3) were, respectively, 5.14 (1.16), 2.93 (1.31) and 4.76 (.99). So, immediately after the mood induction (T2), sadness showed a sharp peak and happiness a sharp decline, but after the food intake (T3) both sadness and happiness returned to near baseline levels. For both sadness and happiness there was a significant effect of time (respectively: $\mathrm{F}(2,56)=118.574, \mathrm{p}<.001, \eta_{p}^{2}=.81$, and $\mathrm{F}(2,56)$ $\left.=53.957, \mathrm{p}<.001, \eta_{p}^{2}=.66\right)$, and for both sadness and happiness the quadratic model reached the highest significance $\left(\mathrm{F}(1,28)=138.075, \mathrm{p}<.001, \eta_{p}^{2}=.87\right.$ and $\left(\mathrm{F}(1,28)=78.672, \mathrm{p}<.001, \eta_{p}^{2}\right.$

\subsubsection{Simple associations and descriptives of variables}

Table 1 shows the Pearson correlations, means and standard deviations of the variables in Study 1. Eating more energy and being more satisfied with the meal was associated with becoming less sad from T2 (after the mood induction) to T3 (after the meal). Being sadder before the mood induction was associated with a lower decrease in sadness after eating. Becoming happier after eating was significantly associated with greater satisfaction from eating, and being happier before the mood induction. Energy intake was also positively associated with eating satisfaction.

It should further be noted (not shown in Table 1) that high emotional eaters ate significantly more food in energy and in grams than low emotional eaters (energy: mean: $204.91(\mathrm{SD}=126.22)$ vs $113.07(\mathrm{SD}=71.79)(\mathrm{p}=.022)$; grams: mean=53.86 $(\mathrm{SD}=46.39$ vs 
$21.80(\mathrm{SD}=17.88)(\mathrm{p}=.019)$, and that high emotional eaters ate marginally more $(\mathrm{p}=.055)$ highly processed food (the sum of the intake of salty peanuts, sweet peanuts, chips, jelly

247 sweets, cereal bar, chocolate, rice bar, and rosquilleta) and significantly more chocolate

$248(\mathrm{p}=.003)$ than low emotional eaters (respectively, highly processed food: mean $=185.81$

$249(\mathrm{SD}=114.46)$ vs $115.16(\mathrm{SD}=74.66)$; chocolate: mean=57.20 $(\mathrm{SD}=44.96)$ vs 14.30

250 ( $\mathrm{SD}=23.59)$. Intake of other individual foods did not differ between groups. Further, high

emotional eaters also reported feeling more guilty after the food intake than did low emotional eaters $($ mean=2.43 $(\mathrm{SD}=1.50)$ versus $1.00(.00)(\mathrm{p}=.004)$. Notably, there were no differences between high and low emotional eaters in eating satisfaction (mean: $2.50(\mathrm{SD}=1.23)$ vs 2.33 $(\mathrm{SD}=.98)(\mathrm{p}=.289)$.

Please insert table 1 about here

\subsubsection{Mediation effects}

With PROCESS, we examined whether the relationship between food intake (X) and decrease in sadness (Model 1) or increase in happiness (Model 2) (Y) was mediated by eating satisfaction (M). We first elaborate on the results for Model 1 (decrease in sadness). In line with the hypothesis, the indirect effect through eating satisfaction was significant $(B=-0.003$; $95 \% \mathrm{CI}=-0.007,-0.0008)$. The full model, containing food intake, the mediator and the covariate, sadness at T2 (after the mood manipulation), was significant $(F(3,25)=8.37$, $\mathrm{p}<.001$ ) and explained 50\% of the variance in sadness at T3 (post food intake). See Figure 1 for the regression coefficient B $(95 \% \mathrm{CI})$ associated with the various paths in the model. Very similar results were obtained when we also included baseline sadness as confounder (indirect effect: $\mathrm{B}=-0.002$ ( $\mathrm{SE}=0.001), 95 \% \mathrm{BC}$ CI $[-0.006,-0.0007])$, or, additionally, guilt as confounder (indirect effect: $\mathrm{B}=-0.002(\mathrm{SE}=0.001), 95 \% \mathrm{BC}$ CI $[-0.007,-0.0006])$. 
Highly similar results were obtained for intake of food in grams, instead of kcal

271 (indirect effect: $\mathrm{B}=-0.007(\mathrm{SE}=0.003), 95 \% \mathrm{BC}$ CI $[-0.02,-0.003])$. Very similar results were

272 also obtained for intake by kcal of high energy-dense food, low-energy dense food, intake by

$273 \mathrm{kcal}$ of sweet food or intake by kcal of salty food, or intake of processed food. Only for intake 274 of unprocessed food (apple and banana) was the indirect effect not significant (data available 275 on request).

For increase in happiness (Figure 2), we found the following results: In line with the hypothesis, the indirect effect through eating satisfaction was significant $(B=0.003 ; 95 \% \mathrm{CI}=$ 0.008, 0.007). The full model, containing food intake, the mediator and the covariate: happiness at T2 (after the mood manipulation) was significant $(F(3,25)=7.18, p<.001)$ and explained $46 \%$ of the variance in happiness at T3 (post food intake). See Figure 2 for the B $(95 \% \mathrm{CI})$ associated with the various paths in the model. Very similar results were obtained when we also included baseline happiness as confounder (indirect effect: $\mathrm{B}=0.003$ $(\mathrm{SE}=0.001), 95 \% \mathrm{BC}$ CI $[0.008,0.007])$, or, additionally, guilt as confounder (indirect effect: $\mathrm{B}=0.003(\mathrm{SE}=0.002), 95 \% \mathrm{BC} \mathrm{CI}[0.001,0.009])$.

Highly similar results were obtained for intake of food in grams, instead of kcal (indirect effect: $\mathrm{B}=.34(\mathrm{SE}=.26), 95 \% \mathrm{BCCI}[.02,1.133]$. Very similar results were also 290 obtained for kcal of intake of energy-dense food, intake of low-energy food, intake by kcal of 291 sweet food or intake by kcal of salty food, intake of processed foods (salty peanuts, sweet 292 peanuts, chips, jelly sweets, cereal bar, chocolate, rice bar, and rosquilleta). Only for intake of unprocessed food (apple, banana) was the indirect effect not significant (results available on 294 request). 


\subsection{Summary of Study 1}

297 Eating was associated with a clear reduction in sadness and increase in happiness.

298 Furthermore, in support of Macht and Mueller (2007a), eating satisfaction acted as a mediator 299 between food intake and i) decrease in sadness and ii) increase in happiness.

300

301

\section{Study 2}

302

\subsection{Overview of Study 2}

For Study 2, we used data from an ongoing so called 'health and physiology' investigation

(van Strien et al., 2012; van Strien, Roelofs \& de Weerth, 2013; van Strien, Ouwens, Engel \& 305 de Weerth, 2014). The data for the additional participants in the present study had been 306 collected between October 2012 and May 2013. Using a within-subject design in females 307 varying in emotional eating, we measured the difference in food intake following a laboratory 308 control task or a stress task, the Trier Social Stress Test (TSST; Kirschbaum, Pirke \& 309 Hellhammer, 1993). We further assessed negative affect during various time points, most 310 importantly during the food intake. For all types of food offered, we assessed, after food 311 intake, the degree to which it was rated as 'lekker' (a typically Dutch word meaning 312 something like 'tasty' or 'yummy'; i.e. measuring 'tastiness'). Earlier analyses on a subsample of the present study revealed that emotional eating 314 status significantly moderated the association between distress and food intake, with low 315 emotional eaters eating less after the stress than after the control task and high emotional 316 eaters eating more (van Strien et al., 2012, 2013, 2014). Furthermore, the significant increase 317 in negative mood after the stressor showed a substantial reduction during food intake.

318 However, whether the tastiness of the food acts as mediator between food intake and the 319 reduction of negative mood during food intake was not yet assessed and also not whether such 
320 a mediation effect is contingent on degree of emotional eating. We expected that the mediation

321 effect of tastiness would be stronger for high than for intermediate or low emotional eaters.

322

\subsection{Method}

324

\subsubsection{Design}

This study is part of an ongoing within-subject experimental study. Results on the

Strien, Herman, Anschutz, Engels, \& de Weerth, 2012; Van Strien, Roelofs \& de Weerth, 2013; van Strien, Ouwens, Engel \& de Weerth, 2014). ${ }^{1}$

Of the additional women that participated in the present study, a total of 17 did not

fulfill the requirement of having extreme values on the pre-test of emotional eating (scores

below 1.82 or above 3.25 , corresponding to the 20 th and 80 th percentile of the Dutch norm group of females). The reason is that we had increasing difficulties in finding participants

with extremely low values on emotional eating (extreme high values were not so much of a problem). Nevertheless, with over $75 \%$ of our sample having extreme values on emotional eating we followed the advice of Whisman \& McClelland (2005) to oversample participants with extreme scores (p.118), to enhance the chance of finding possible interaction effects 338 (McClelland \& Judd, 1993). Following Preacher (2015) to preserve ... "the individual differences within each extreme" (o.c. p2), we kept the data on emotional eating in the present 340 study in their original, continuous form, instead of using the earlier dichotomy of low versus high emotional eating.

\footnotetext{
${ }^{1}$ Footnote 1 . The data of these previous publications had been collected in spring and autumn of 2010, and respectively spring 2012 (van Strien et al, 2012; Van Strien et al., 2013; van Strien et al., 2014). They address the moderation of distress induced eating by emotional eating scores, cortisol reactivity and distress induced emotional eating and hunger, inhibitory control and distress-induced emotional eating.
} 
342

343

344

345

346

347

348

349

350

351

352

353

354

355

356

357

358

359

360

361

362

363

364

365

366

The participants were subjected to a control task and a stress task (TSST) on two consecutive days. The TSST involves speaking in front of a jury coupled with an arithmetic challenge. Because the stress condition is perceived by some subjects as very stressful, we deliberately started with the control condition and did not counterbalance the order of the two conditions. We were concerned that we would lose too many subjects when we started with the stress condition because they would refuse to come back the following day for the control condition. We were also concerned that the control condition would suffer from carry over effects if we started with the stress condition (see also footnote 4 in van Strien, Ouwens, Engel \& de Weerth, 2014).

The study protocol was approved by the ethical board of the Faculty of Social Sciences of the Radboud University Nijmegen (ECG 29042010). Before participating, the participants filled out informed consent forms.

\subsubsection{Participants}

Participants were recruited from a pool of female students taking introductory psychology or pedagogy courses who had completed the emotional eating scale in class or on our research participant portal. Eighty-four females participated but complete information was only obtained from 74 women: 22 low emotional eaters, 35 high emotional eaters and 17 women with intermediate scores on the scale for emotional eating. Their mean age was 23.08 $(\mathrm{SD}=2.29)$ years and their mean BMI (body mass index; weight/height* height) was 21.05 $(\mathrm{SD}=2.57) \mathrm{kg} / \mathrm{m}^{2}$.

\subsubsection{Procedure}

The sessions were scheduled on consecutive weekdays between 11 a.m. and 3 p.m. In the control condition, participants had to rate various fabrics (e.g. fur and silk) on various 
367 attributes (e.g. softness and warmth) for 15 minutes. After this, they were led to a separate

368 room to fill out questionnaires, the first one being a questionnaire on mood, at a table which also held a glass of water and four bowls filled with, respectively, white grapes, pieces of carrot, M\&Ms (small sugar-coated chocolate sweets) and pieces of buttercake (dense, buttery, sweet baked cake). Participants were invited to help themselves to the water and the food with the words: "Please help yourself to the water and the food. You have earned it". In the stress condition, the participants were subjected to a modified version of the TSST (Kirschbaum et al., 1993), which consisted of preparing (5 min) and delivering (5 min) a videotaped speech, followed by a serial subtraction task ( $5 \mathrm{~min})$. The speech and subtraction task were presented in front of a two-person jury who sat behind a table and wore white doctor's coats. Because the TSST originally has a three-person jury (instead of our present two-person jury), to enhance the stress, the participant had to stand without shoes on a Wii C balance board, in front of the jury. After the stress task, the experimenter asked the participant to wait for the jury's judgment of the participant's performance - in this manner the stressfulness of the public speaking task was extended by a prolonged period of waiting for the results - and to fill out a set of questionnaires. After 15 min the experimenter returned to communicate a positive judgment by the jury, after which the participants were led to the separate room to fill out a further set of questionnaires, the first one being the questionnaire on mood. This questionnaire measured mood during the food intake: participants were invited to help themselves to the water and the food on the table with the same words as on the previous day. After 20 min the experimenter returned to administer the questions on 'lekker' (tastiness). The final task for the experimenter was to measure the weight and height of the participant, and debrief, thank and pay the participants with course credits. Before debriefing, the participants were questioned on the perceived purpose of the study and none of the participants was aware 
391

392

393

394

that their food intake was being measured. It should further be noted that the experimenter was kept blind to the emotional eating status of the participants.

\subsubsection{Measures}

Emotional eating was assessed with the Dutch Eating Behaviour Questionnaire (DEBQ; Van Strien, 2010; Van Strien, Barrada \& Cebolla, 2016). The DEBQ emotional eating scale has 13 items (e.g., "Do you have a desire to eat when you are irritated") and has to be rated on a 5-point scale with response categories that range from 1 'never' to 5 'very often'. The DEBQ has been rated as 'up to the mark' or 'good' by the Dutch Committee on Tests and Testing (COTAN) on all EFPA (European Federation of Psychologists' Association) criteria (e.g. norms, reliability (internal consistency, test-re-test) and validity (dimensional validity, construct validity and criterion validity) (COTAN, 2013). See for the internal consistency, factorial, construct and predictive validity: Van Strien, 1996; Van Strien, Herman \& Anschutz, 2012; Van Strien \& van de Laar, 2008; Van Strien et al., 2012; Barrada, van Strien \& Cebolla, 2016.

Mood was measured on both days, upon arrival and at three more time points: immediately after the task, after the message of having to wait for the jury's judgement on the performance, and during the food intake using the Positive and Negative Affect Schedule (PANAS; Watson, Clark, \& Tellegen, 1988). This instrument measures, on a 5-point (1= 'not at all' to 5= 'extremely') scale, the degree to which participants experienced 10 positive and 10 negative emotions, thus generating orthogonal measures of positive and negative affect.

Hunger was also measured on both the control and the stress day, by inserting the item 'hungry' among the 5-point PANAS items. For the present study only the hunger assessment during the food intake on the control and stress days was of relevance. 
Tastiness ('Lekker'). For each of the food types (carrots, grapes, M\&M's and

buttercake) 'lekker' (equivalent to tastiness, i.e. rated palatability) was assessed with a 5-point $(1=$ 'not at all' to $5=$ 'extremely') scale. The questions on 'lekker' were assessed after the food consumption on the stress day.

For all scales, scale scores were obtained by calculating the mean of the items of a scale.

Food intake. For both the control and the stress day, before and after the participants ate, the individual plates with food (grapes, carrots, buttercake and M\&M's) were weighed with a professional scale. We then translated weight into energy (kcal) for each food type and summed the caloric intake over the four types of food. Since hardly any grapes and carrots were eaten on average (see Table 2), in additional analyses we also used the kcal of the snack food (the sum in kcal of cake and M\&M's). This allowed us to test for changes specifically in intake of sweet fatty 'comfort food'.

\subsubsection{Data analysis}

With repeated measures GLM we conducted manipulation checks by assessing the effect of time on the negative and positive mood values in the stress condition, in addition to the effect of condition (control vs stress) on the mood values over time. Greenhouse-Geisser corrections were applied where appropriate. Mediation and moderated mediation were assessed with the PROCESS macro of SPSS version 23.0, developed by Hayes (2013 (model 4 and model 7). Moderated mediation was tested with Hayes' index of moderated mediation (Hayes, 2015). We used bootstrapping with 5,000 samples. All variables were centred before computing interaction terms. Because the manipulation check (see 3.3.1) revealed no condition $\mathrm{x}$ time interaction on positive affect we only conducted analyses for negative affect. Because the manipulation check (3.3.1) revealed that the quadratic model reached the highest significance 
in the stress condition, we assessed the affect reactivity during the stress condition (the

441 dependent variable $\mathrm{Y}$ ) with the area under the curve with respect to the ground

\section{$442 \quad\left(\mathrm{AUCg}\right.$-stress). ${ }^{2}$}

The dependent variable (Y) was affect reactivity during the stress condition (AUCg),

444 the independent variable $(\mathrm{X})$ was the difference in food intake between the stress and the

445 control condition in kcal (henceforth delta kcal; a positive value meaning more food intake in

446 the distress than in the control condition), the mediator (M) was tastiness and the moderator

447 (W) was degree of emotional eating (assessed well before the study in class or at our research 448 portal).

\footnotetext{
${ }^{2}$ Footnote: AUCg is a well-known summary indicator of repeated measurements (e.g. the four negative affect values during stress and food intake in the present study). In the present study the AUCg_stress showed a correlation, $r=0.87$, with the negative affect value during food intake.
} 
461 with the negative affect value during the food intake (T4) and using the highest negative

462 affect value after the stressor (T2 or T3) as a covariate.

\section{3.3. Results}

\subsubsection{Manipulation check.}

Negative mood. Figure 3 shows the values for negative mood in the control and the stress condition upon arrival (T1), immediately after the task (T2), after the message of having to wait for the jury's judgement on the performance (in the stress condition) (T3), and during the food intake (T4). In both conditions the values on negative mood were significantly affected by time (control condition: $\mathrm{F}(2.482,181.202)=9.266, \mathrm{p}<.001, \eta_{p}^{2}=.113$; stress condition: $\mathrm{F}$ $\left.(2.010,146.704)=47.946, \mathrm{p}<.001, \eta_{p}^{2}=.40\right)$. In the control condition, negative mood showed slow improvement; here the linear model reached the highest significance $(F(1,73)=17.026$, $\left.\mathrm{p}<.001, \eta_{p}^{2}=.19\right)$. In the stress condition, negative mood showed a sharp peak immediately after the stressor but markedly improved during food intake; here, the quadratic model reached the highest significance $\left(\mathrm{F}(1,73)=68.721, \mathrm{p}<.001, \eta_{p}^{2}=.49\right)$. As could be expected, there were significantly higher values of negative mood in the stress than in the control condition on all time points except T1 (Figure 3). The overall moderator effect of the stress condition on the mood values over time was significant $\left(\mathrm{F}(3,69)=23.950, \mathrm{p}<.001, \eta_{p}^{2}=.51\right)$. In regard to positive mood, there was no significant effect of time in the control condition (F $\left.(1.051,75.638)=2.246, \mathrm{p}=.137, \eta_{p}^{2}=.030\right)$ and a borderline non-significant effect of time in the stress condition $\left(\mathrm{F}(1.826,133.297)=3.107, \mathrm{p}=.053, \eta_{p}^{2}=.041\right)$; there also was no significant overall moderator effect of the stress condition on the positive mood values over time $\left(\mathrm{F}(1.102,79.322)=1.860, \mathrm{p}=.177, \eta_{p}^{2}=.026\right)$. 
Please insert Figure 3 about here

$488 \quad 3.3 .2$. Simple associations between variables

489 Table 2 shows the Pearson correlations, means and standard deviations of the variables in 490 Study 2. Negative mood reactivity during stress (AUCg stress) showed no significant 491 association with total energy intake (kcal), nor from the sweet fatty snack food (butter cake 492 plus M\&M). It was only significantly associated with decrease in negative affect in the control condition (participants with a larger fall in negative affect in the control condition had 494 a bigger increase in negative affect in the stress condition, suggesting a mood lability pattern) 495 and with hunger during food intake in the stress condition (Table 2). Intake of energy (total 496 intake and intake from snacks) was significantly positively associated with hunger during 497 food intake in the stress condition. Not shown in Figure 3 is that tastiness showed a 498 significant positive association with the intake of snack food in the control condition $(\mathrm{r}=0.29$, $\mathrm{p}=.012$ ) but no significant association with the intake of snack food in the stress condition $500(\mathrm{r}=\mathrm{0.004}, \mathrm{p}=.971)$. However, these simple associations do not account for level of emotional 501 eating.

Please insert Table 2 about here

\section{3.3.3. Mediation effects}

506 Using the PROCESS (model 4), we examined whether the relationship between food intake 507 (delta kcal; X) and negative mood reactivity during stress (AUCg stress; Y) was mediated by 508 tastiness (M). The 90\% CI indicated that the indirect effect through tastiness was not 509 significant $(\mathrm{B}=-.0004(\mathrm{SE}=.0005), 90 \% \mathrm{BC}$ CI $[-.002, .0002])$, and was also not significant 
510 when we controlled for affect reactivity in the control condition $(n=72)(B=-.0004$,

\subsubsection{Moderated mediation analyses}

514 Figure 3 shows the B $(95 \% \mathrm{CI})$ associated with the various paths in the moderated mediation 515 analysis (PROCESS, model 7) with emotional eating as moderator variable of the mediation 516 model of tastiness (M) between food intake (delta kcal; X) and negative mood reactivity 517 during distress (AUCg stress; Y). The index of moderated mediation was significant at 95\% $518 \mathrm{CI}(\mathrm{B}=.0007,(\mathrm{SE}=.0005) 95 \% \mathrm{BC}$ CI $[.00001, .00234])$. Inspection of the conditional indirect 519 effects for low, intermediate and high emotional eaters revealed that there was a $90 \% \mathrm{CI}$ 520 significant positive mediation effect for tastiness for the high emotional eaters $(B=.0006$ $521(\mathrm{SE}=.0005), 90 \% \mathrm{BC} \mathrm{CI}[.00001, .002])$, a non-significant mediation effect for the 522 intermediate emotional eaters ( $\mathrm{B}=-.0003$ ( $\mathrm{SE}=.0004), 90 \%$ BC CI $[-.001, .0002])$, and a $90 \%$ 523 CI significant negative mediation effect of tastiness for the low emotional eaters $(B=-.0011$ $524(\mathrm{SE}=.0009), 90 \%$ BC CI [-.003,-.00001]). Also, when in an additional analysis we controlled 525 for affect reactivity in the control condition $(n=72)$, the index of moderated mediation was 526 significant at $95 \% \mathrm{CI}(\mathrm{B}=.0008(\mathrm{SE}=.0005) 95 \% \mathrm{BC}$ CI $[.00007, .002])$. Moreover, here there 527 was a $90 \%$ CI significant positive mediation effect of tastiness for the high emotional eaters, a non-significant effect for tastiness for the intermediate emotional eaters, and a 90\% BC CI 529 significant negative mediation effect of tastiness for the low emotional eaters.

Please Insert Figure 4 about here

In further additional moderated mediation analyses, we controlled for hunger during 534 food intake in the control and stress condition (in addition to affect reactivity in the control 
535 condition). The index of moderated mediation was significant at the $90 \% \mathrm{CI}(\mathrm{B}=.0005$

$536(\mathrm{SE}=.0004) 90 \% \mathrm{BC} \mathrm{CI}[.0003, .003])$. The results went in the same direction (negative

537 effects in low, no effects in the intermediate and positive effects in the high emotional eaters),

538 but the mediation effect of tastiness was significant only for the low emotional eaters at $90 \%$

539 CI: $\mathrm{B}=-.0008(\mathrm{SE}=.0007) 90 \%$ BC CI [-.003, -.00001]. Highly similar results were obtained

540 for intake of food in grams, instead of kcal, though the index of moderated mediation was only significant at 90\% CI ((B=.0008, $(\mathrm{SE}=.0008) 90 \% \mathrm{BC}$ CI $[.000003, .003])$.

We also conducted moderated mediation analyses where we replaced the total amount

543 of kcal with the amount of kcal from intake of cake plus M\&M's (i.e. the sweet and fatty

544 foods). The index of moderated mediation of the full model (controlling for affect reactivity in 545 the control condition, $(n=72))$, was significant at $95 \% \mathrm{CI}(\mathrm{B}=.0008(\mathrm{SE}=.0006) 95 \% \mathrm{BC} \mathrm{CI}$

$546[.0006, .002])$, with a $90 \%$ CI significant positive mediation effect of tastiness between snack 547 intake and mood improvement for high emotional eaters $(\mathrm{B}=.0007(\mathrm{SE}=.0005) 90 \% \mathrm{BC} \mathrm{CI}$ $548[.00004, .002])$, a non-significant effect for tastiness for the intermediate emotional eaters $549(\mathrm{~B}=-.0002(\mathrm{SE}=.0004) 90 \% \mathrm{BC}$ CI $[-.001, .0002])$ and a 90\% CI significant negative 550 mediation effect for low emotional eaters $(\mathrm{B}=-.0012(\mathrm{SE}=.0009) 90 \% \mathrm{BC}$ CI [-.004,-.0007]).

552 3.3.5. Post-hoc mediation of hunger

553 In additional post hoc analyses we also assessed mediation and moderated mediation with 554 hunger instead of tastiness as mediator (hunger during the food intake in the stress condition, 555 controlling for hunger in the control condition). In the full model (additionally controlling for 556 affect reactivity in the control condition $(n=72))$, the indirect effect through 'hunger' was 557 significant at the $90 \% \mathrm{CI}(\mathrm{B}=.0009(\mathrm{SE}=.0008), 90 \% \mathrm{BC}$ CI $[.00004, .003])$, indicating 558 borderline significant mediation. There was no moderated mediation, because the index of 
moderated mediation was, in this full model, not significant at $90 \% \mathrm{CI}(\mathrm{B}=.0004(\mathrm{SE}=.0005)$

3.3.6. Post-hoc analysis with a single point measure for 'mood recovery during eating' In additional post-hoc analyses we calculated a different and potentially more sensitive but single point measure for 'mood recovery during eating' by replacing our dependent variable (AUCg) with only the negative affect value during food intake (T4), and using the highest negative affect value after the stressor (T2 or T3) as a covariate. The results went in the same direction.

In the moderated mediation analysis with total amount of intake (kcal), the index of moderated mediation of the full model (controlling for affect reactivity in the control condition $(\mathrm{n}=74))$ was significant at $95 \% \mathrm{CI}(\mathrm{B}=.1183(\mathrm{SE}=.08187) 95 \%$ BC CI [.0001, $.3182]$ ), with a $95 \%$ CI significant positive mediation effect of tastiness between food intake and mood improvement for high emotional eaters $(\mathrm{B}=.0647(\mathrm{SE}=.0484) 95 \% \mathrm{BC}$ CI $[.0007$, .2139]), and non-significant effects (also not significant at 90\% CI) for tastiness for the intermediate and low emotional eaters (respectively, $\mathrm{B}=-.0671(\mathrm{SE}=.0637) 95 \% \mathrm{BC}$ CI [$.2149, .0257]$ and $\mathrm{B}=-.1990(\mathrm{SE}=.1498) 95 \% \mathrm{BC}$ CI $[-.5481, .0119])$. Highly similar results were obtained when we did not control for affect reactivity in the control condition.

In the moderated mediation analysis with amount of intake of kcal from intake of cake plus M\&M's (i.e. the sweet and fatty foods), the index of moderated mediation of the full model (controlling for affect reactivity in the control condition $(\mathrm{n}=74)$ ) was also significant at 95\% CI (B=.1367 ( $\mathrm{SE}=.0870)$ 95\% BC CI $[.0030, .3378])$, with a 95\% CI significant positive mediation effect of tastiness between snack intake and mood improvement for high emotional eaters $(\mathrm{B}=.0755(\mathrm{SE}=.0524) 95 \% \mathrm{BC}$ CI $[.0034, .2368])$, and non-significant effects (also not significant at $90 \% \mathrm{CI}$ ) for tastiness for the intermediate and low emotional eaters 
584 (respectively, $\mathrm{B}=-.0768(\mathrm{SE}=.0697) 95 \% \mathrm{BC}$ CI $[-.2353, .03146]$ and $\mathrm{B}=-.2291(\mathrm{SE}=.1606)$

$58595 \%$ BC CI $[-.5666, .0094])$. Highly similar results were obtained when we did not control for 586 affect reactivity in the control condition.

\section{3.4. Summary and conclusion for Study 2}

589 In this study, where negative affect was assessed during the food intake, we found that the 590 mediation effect of tastiness between food intake and distress induced mood reactivity was 591 contingent on (moderated by) emotional eating scores. Whereas high emotional eaters showed reactivity during distress.

4. General discussion

600

In two studies, we assessed the possible mediating effect of eating satisfaction or 'lekker' (tastiness) between food intake and mood improvement respectively after or during the food 604 'lekker' is contingent on emotional eating, with expected stronger mediation effects in high 605 than in intermediate or low emotional eaters. In Study 1, where mood was assessed after the 606 food intake, we found, as expected, significant mediation, i.e. the satisfaction from eating 607 explained the impact of eating snack foods on both reduced sadness and increased happiness. In Study 2, we did not find significant overall mediation of 'lekker' or tastiness between food 
intake and mood improvement. Instead we found that the mediation effect of tastiness was

contingent on emotional eating, with a significant positive mediation effect of tastiness in the

high emotional eaters, no significant mediation effect of 'tastiness' in the intermediate

emotional eaters and a significant negative mediation effect of tastiness in the low emotional eaters on the change in negative affect.

The effects for high versus low emotional eaters in Study 2 thus went in opposing directions, which may explain the absence of a mediation effect of tastiness between food intake and mood improvement in the entire sample (the combined sample of high, intermediate and low emotional eaters). We found a similar moderated mediation when we replaced the energy intake from all foods with the energy intake from solely the sweet fatty snack food (cake plus M\&M). The positive mediation effect of tastiness in the high emotional eaters is in line with the finding by Macht and Mueller (2007a). In that study, the mood elevation immediately after eating the palatable chocolate was more pronounced in the high than in the low emotional eaters (as determined by a median split of the emotional eating scale of the DEBQ). The negative mediation effect of tastiness in the low emotional eaters that we found with both food intake and intake of cake plus M\&M, means that tastiness acted as a suppressor variable in this subgroup: inclusion of tastiness in the regression model of the low emotional eaters increased the effect of food intake on negative affect reactivity during distress.

The post-hoc finding that there was no significant moderated mediation when we replaced the mediator tastiness with 'hunger during food intake' is in line with the observation by Reichenberger et al. (2018, p.61) "that it is the hedonic, not the homeostatic system that is affected by emotional eating”. In other words, for people with a high tendency towards emotional eating, palatability/taste may be more important than hunger/satiety in influencing their mood after eating. Furthermore, this uncoupling of the hedonic from the homeostatic 
exposes emotional eaters to greater risk of overconsumption (Hetherington et al., 2013).

However, this finding does not support the earlier psychosomatic proposal (Bruch, 1973) that comfort eating may arise from confusion of hunger with affect.

The positive mediation effect of tastiness between food intake and mood improvement 638 during food intake in the high emotional eaters is in line with the results of a functional 639 magnetic resonance imaging (fMRI) study (Bohon, Stice \& Spoor, 2009): increased activation 640 of brain reward pathways in female emotional eaters in response to anticipation and 641 consumption of a chocolate milkshake during negative mood indicates that for emotional 642 eaters food may be more rewarding or pleasurable when they are in a negative mood state. A 643 further remarkable finding in that same study was that there were no changes in affect in 644 response to the anticipation or taste of the food. This suggests that the eating did not actually 645 alleviate negative affect, a result that would be in line with the studies showing that the 646 improvement in mood is at best only short lived (Macht \& Mueller, 2007a, Daever et al., 647 2003), and may even become worse after some time (Haedt-Matt et al., 2014).

In Study 1, we assessed the improvement in mood immediately after food intake:

653 ate more of the highly processed snack foods, and chocolate, than low emotional eaters, 654 replicating earlier findings (Gibson, 2012), although this group difference was not apparent 655 for intake unprocessed apple and banana. It is thus worth noting that the mediation by eating 656 satisfaction of the reduction in sadness after snack intake was only significant for the 657 processed foods, suggesting that the manufactured palatability of processed foods may be 658 more effective in comforting than at least unprocessed fruit. 
The sample size of Study $1(n=29)$ did not permit us to determine whether the

mediation effect in Study 1 is also contingent on emotional eating status, but in a future study

it would be of interest to determine whether similar results are obtained when mood is assessed immediately after versus during the food intake.

One possible explanation for the finding in low emotional eaters in Study 2 (though not significant in the additional post hoc analysis) is that during stress, low emotional eaters would normally have less appetite for food, but very tasty food could counteract this tendency, so might set up a motivational conflict that could worsen their mood (Gibson, 2012). To put it another way, low emotional eaters reflect their enjoyment or satisfaction from eating the meal in their mood changes (Hetherington, Cunningham, Dye, Gibson et al., 2013), whereas high emotional eaters may have a more complex relationship with their post-meal mood states that uncouples them from the level of satisfaction arising from eating the meal. For example, habitual use of palatable food for emotional comfort may focus attention of high emotional eaters away from the satisfaction of eating and towards post-meal mood change. Alternatively, emotional eaters may experience improved mood induced by 'eating satisfaction' only during and not after eating. For example, in a study where only brief tastes of food samples were allowed, so that meaningful eating satisfaction could not occur, tasting energy-dense foods induced negative emotions in women who were overweight and emotional eaters (Macht, Gerer \& Ellgring, 2003). Similarly, self-confessed 'chocolate addicts' reported increased negative affect after eating chocolate (Macdiarmid \& Hetherington, 1995). Moreover, in 931 Californians, greater habitual chocolate consumption was strongly associated with more depressive symptoms, particularly in women (Rose, Koperski \& Golomb, 2010), implying that chocolate may provide only transient relief from negative affect, as the experimental study of Macht and Mueller (2007a) also found. Furthermore, it has been observed that, in chocolate cravers, images of chocolate 
684

simultaneously induced appetitive and aversive motivational states (assessed by physiological responses; Rodriguez, Fernandez, Cepeda-Benito, \& Vila, 2005). Indeed, a recent theoretical model for stress-induced eating, in contrast to the "affect reduction" model, proposed that

\section{7}

stress may actually reduce the pleasure of eating highly palatable foods, at least in susceptible

688 individuals, instead amplifying learned motivational and attentional responses to the presence 689 of such foods, at the expense of more cognitively demanding goal-dependent control on eating (Pool, Delplanque, Coppin \& Sander, 2015). In other words, when stressed, our habitual and long-established food preferences are evoked, predominantly for energy-rich sweet and/or fatty foods. It is therefore worth noting that in Study 2, whereas tastiness was positively associated with snack intake in the control condition, it was unrelated to intake after stress (3.3.2).

A major limitation of both study 1 and study 2 is that the assessment of the mediating variables eating satisfaction (Study1) and tastiness (Study 2) between food intake and change in mood took place after the last assessment of mood. For an assessment of mediation potentially allowing assessment of causal connections, eating satisfaction and tastiness would need to be assessed well before the last measurement of mood. For both study 1 and study 2, it is therefore also possible that the change in mood after or during the food intake affected the eating satisfaction or tastiness ratings, whilst they also could have been reciprocally associated. However, our model of mediation was theory driven, and inspired by earlier results by Macht \& Mueller (2007a). Furthermore, the participants' postprandial judgement of both eating satisfaction and tastiness are likely to involve some reflection on and recollection of the experience of the foods they have just eaten, so are not merely assessments of their impressions at that exact moment somehow independent of recent experience. Therefore, though our results preclude causality, they are nonetheless informative and may provide a good basis for future studies that are able to identify the unfolding of the associations over 
time. ${ }^{3}$ In the same line, a further limitation of Study 2 is that 'lekker', though assessed at the end of the study, may have influenced the amount of food eaten, so that the reverse direction

of the mediation model could be true; however, tastiness was not associated with intake after stress, making this explanation unlikely.

Another limitation is that we cannot rule out the possibility that, for reasons of social desirability, people may have denied emotional eating. Still, scores on the emotional eating scale earlier showed predictive validity for greater eating during stress in the same datasets, reducing this concern. In addition, different measures of pleasantness of the food were used in the two studies (e.g., eating satisfaction versus 'lekker'), and an important difference between the two studies is that Study 1 used a sadness induction whereas Study 2 used a stress procedure.

A limitation to generalization is that the experiments were conducted in predominantly normal-weight young female students, and that the number of participants in Study 1 was rather small. Therefore, our results need replication in overweight participants and may not be applicable to men. Finally, the present findings could benefit from replication in larger samples in more natural settings.

\section{General Conclusion}

In non-obese young women, food experienced as highly palatable and satisfying may provide comfort, i.e. reduce negative affect, specifically for high emotional eaters, at least during eating.

\footnotetext{
${ }^{3}$ This may, however, not be as easy as it sounds. For study 2, where this last mood assessment took place during the food intake, this would for example mean that also the assessment of tastiness should have taken place during the food intake (for example with a bogus taste test). A problem with such a taste test is that it could make people aware that their food intake is being measured, which could affect the amount of food consumed. This could be particularly true for people with high scores on emotional eating (Van Strien et al., 2012, p283, footnote 7)
} 
731 Conflict of interest

Tatjana van Strien has a copyright and royalty interest in the Dutch Eating Behaviour

Questionnaire (DEBQ) and manual.

734

735 Role of funding source

736 Study 1 was funded in part by the Ministerio de Ciencia e Innovación (Plan Nacional de

737 Investigación Científica, Desarrollo e Innovación Tecnológica 2008-2011) in the Project

738 (PSI2008-04392/PSIC). Funding of L.H.H. Winkens was provided by the European Union

739 FP7 MoodFood Project 'Multi-country collaborative project on the role of Diet, Food-related

740 behaviour, and Obesity in the prevention of Depression' (grant agreement no. 613598).

742 Acknowledgement

743 CIBERObn is an initiate of the ISCIII

744 Contributors

$745 \mathrm{RB}$ and AC oversaw the data collection of Study 1. TvS oversaw the data collection of Study

7462 , conducted all analyses and prepared the first draft of the manuscript. LG was responsible

747 for the second and final drafts of the manuscript. LW prepared the manuscript for submission.

748 All authors commented and contributed on drafts of the manuscript and approved the final

749 manuscript.

750

751 References

752 Agras, W. S. \& Telch, C. F. (1998). The effects of caloric deprivation and negative affect on 753 binge eating in obese binge-eating disordered women. Behavior Therapy, 29, 491-503. 
754 Andersen, B, V., \& Hyldig, G. (2015). Consumers' views on determinants to food satisfaction. A qualitative approach. Appetite, 95, 9-16.

Barrada, J. R., van Strien, T., \& Cebolla, A. (2016). Internal structure and measurement invariance of the Dutch Eating Behavior Questionnaire (DEBQ) in a (nearly) representative Dutch Community Sample. European Eating Disorders Review, 24, 503-509. doi: 10.1002/erv.2448.

Berg, K. C., Crosby, R. D., Cao, L., Crow, S. J., Engle, S. J., Wonderlich, S. A., \& Peterson, C. B. (2015). Negative affect prior to and flowing overeating-only, loss of control eating only, and binge eating episodes in obese adults. International Journal of Eating Disorders, 48, 641-653.

Berg, K. C., Cao, L., Crosby, R. D., Engel, S. G., Peterson, C. B., Crow, S. J . . . Wonderlich, S. A. (2017). Negative affect and binge eating: reconciling differences between two analytic approaches in ecological assessment research. International Journal of Eating Disorders, 50, 1222-1230.

Bohon, C., Stice, E., \& Spoor, S. (2009). Female emotional eaters show abnormalities in consummatory and anticipatory food reward: A functional magnetic resonance imaging study. International Journal of Eating Disorders, 42, 210-221.

Booth, D. A. (1990). How not to think about immediate dietary and postingestional influences on appetites and satieties. Appetite, 14(3), 171-179.

Bruch, H. (1973). Eating disorders. New York: Basic Books.

Cebolla, A., Barrada, J. R., Van Strien. T., Baños, R. M., \& Oliver, L (2014).

Validation of the Dutch Eating Behavior Questionnaire (DEBQ) in a sample of Spanish women. Appetite, 73, 58-64.

COTAN, 2013. Beoordeling Nederlandse Vragenlijst voor Eetgedrag, NVE [Review Dutch Eating Behaviour Questionnaire, DEBQ]. Utrecht: COTAN/NIP. 
779 Daever, C. M., Miltenberger, R. G., Smyth, J., Meidinger, A., \& Crosby, R. (2003). An evaluation of affect and binge eating. Behavior Modification, 27, 578-599.

Gibson, E. L. (2012). The psychobiology of comfort eating: Implications for pharmacological interventions. Behavioral Pharmacology, 23, 442-460.

Glymour, M. M., Weuve, J. \& Chen, J. T. (2008). Methodological challenges in causal research on racial and ethnic patterns of cognitive trajectories: measurement, selection and bias. Neuropsychological Review, 18, 194-213.

Gold, P. W., \& Chrousos, G. P. (2002). Organization of the stress system and its dysregulation in melancholic and atypical depression: high vs low CRH/NE states. Molecular Psychiatry, 7(3), 254-275.

Goldschmidt, A. B., Engel, S. G., Wonderlich, S. A., Crosby, R. D., Peterson, C. B., Le Grange D., .. . Mitchel, J. E. (2012). Momentary affect surrounding loss of control and overeating in obese adults with and without Binge Eating Disorder. Obesity, 20, 1206-1211.

Hayes, A. F. (2013). Introduction to mediation, moderation, and conditional Process analysis, A regression-based approach. New York, London: The Guilford Press.

Hayes, A. F. (2015). An index and test of linear moderated mediation. Multivariate Behavioral Research, 50, 1-22.

Haedt-Matt, A. A. \& Keel, P. K. (2011). Revisiting the affect regulation model of binge eating: a meta-analysis of studies using ecological momentary assessment. Psychological Bulletin, 137, 4, 660-681.

Haedt-Matt, A., Keel, P. K., Racine, S. E., Burt, S. A., Hu, J., Y., Boker, S., . . Klump, K. L. (2014). Do emotional eating urges regulate affect? Concurrent and prospective associations and implications for risk models of binge eating. International Journal of Eating Disorders, 47, 847-877. 
804

805 806

Hetherington, M. M., Cunningham, K., Dye, L., Gibson, E. L., Gregersen, N. T., Halford, J. C., .. . Van Trijp, H. C. (2013). Potential benefits of satiety to the consumer: scientific considerations. Nutrition Research Reviews, 26(1), 22-38. doi: $10.1017 / \mathrm{S} 0954422413000012$

Hilbert, A., \& Tuschen-Caffier, B. (2007). Maintenance of binge eating through negative mood: A naturalistic comparison of binge eating disorder and bulimia nervosa. International Journal of Eating Disorders, 40, 521-530. Doi:10:1002/wat.20401

Kirschbaum, C., Pirke, K. M. \& Hellhammer, D. H. (1993). The Trier Social Stress Test -a tool for investigating psychosocial stress responses in a laboratory setting. Neuropsychobiology, 28, 76-81.

Koenders P., \& Van Strien, T. (2011). Emotional eating rather than lifestyle behavior drives weight gain in a prospective study in 1562 employees. Journal of Occupational and Environmental Medicine, 53, 1287-1293.

Macdiarmid, J. I., \& Hetherington, M. M. (1995). Mood modulation by food - an exploration of affect and cravings in chocolate addicts. British Journal of Clinical Psychology, 34, $129-138$.

Macht, M. \& Simons, G. (2000). Emotions and eating in everyday life. Appetite, 35, 65-71.

Macht, M., \& Mueller, J. (2007a). Immediate effects of chocolate on experimentally induced mood states. Appetite, 49, 667-674.

Macht, M., \& Mueller, J. (2007b). Interactive effects of emotional and restrained eating in responses to chocolate and affect. The Journal of Nervous and Mental Disease, 195, 1024-1026.e.

Macht, M., Gerer, J., \& Ellgring, H. (2003). Emotions in overweight and normal-weight women immediately after eating foods differing in energy. Physiology \& Behavior, 80(2-3), 367-374. doi: DOI 10.1016/j.physbeh.2003.08.012 
829 McClelland, G. H., \& Judd, C. M. (1993). Statistical difficulties of detecting interactions and moderator effects. Psychological Bulletin, 114, 376-390.

McKenna, R. J. (1972). Some effects of anxiety level and food cues on the eating behaviour of obese and normal subjects: A comparison of the Schachterian and psychosomatic conceptions. Journal of Personality and Social Psychology, 22, 311-319.

Oliver, G, Wardle, J., \& Gibson, E. L. (2000). Stress and food choice: A laboratory study. Psychosomatic Medicine, 62, 853-865.

Pool, E., Delplanque, S., Coppin, G., \& Sander, D. (2015). Is comfort food really comforting? Mechanisms underlying stress-induced eating. Food Research International, 76(2), 207-215. doi: 10.1016/j.foodres.2014.12.034

Preacher, K. J. (2015). Extreme groups designs. In R.L. Cautin \& S.O. Lilienfield (Eds). The Encyclopedia of Clinical Psychology (Vol 2, pp 1189-1192). Hoboken, NJ: John Wiley \& Sons, Inc.

Ranzenhofer, L. M., Hannallah, L., Field, S. E., Shomaker, L. B., Stephens, M., Sbrocco, T., . . . Blechert, J. (2013). Pre-meal affective state and laboratory test meal intake in adolescent girls with loss of control eating. Appetite, 68, 30-37.

Reichenberger, J., Kuppens, P., Liedlgruber, M., Wilhelm, F. H., Tiefengrabner, M., Ginzinger, S., \& Blechert, J. (2018). No haste, more taste: An EMA study of the effects of stress, negative and positive emotions on eating behavior. Biological Psychology, 131, 54-62. doi.org/10.1016/j.biopsycho,2015.09.002

Rodriguez, S., Fernandez, M. C., Cepeda-Benito, A., \& Vila, J. (2005). Subjective and physiological reactivity to chocolate images in high and low chocolate cravers. Biological Psychology, 70(1), 9-18. doi: 10.1016/j.biopsycho.2004.10.001 
852 Rose, N., Koperski, S., \& Golomb, B. A. (2010). Mood food: chocolate and depressive symptoms in a cross-sectional analysis. Archives of Internal Medicine, 170(8), 699703. doi: 10.1001/archinternmed.2010.78

Schachter, S., Goldman, R., \& Gordon, A. (1968). Effects of fear, food deprivation and obesity on eating. Journal of Personality and Social Psychology, 10, 91-97.

Slochower, J. (1976). Emotional labeling and overeating in obese and normal weight individuals. Psychosomatic Medicine, 36, 131-139.o

Slochower, J., Kaplan, S.P. (1980). Anxiety, perceived control and eating in obese and normal weight persons. Appetite, 1, 75-83.

Stein, R. I., Kenardy, J., Wiseman, C. V., Dounchis, J. Z., Arnow, B. A., \& Wilfley, D. E. (2007). What's driving the binge in binge eating disorder? A prospective examination of precursors and consequences. International Journal of Eating Disorders, 34, 349360. Doi:10.1002/eat.10194.

Stone, A. A. \& Shiffman, S. (1994). Ecological momentary assessment (EMA) in behavioral medicine. Annals of Behavioral Medicine, 16, 199-202.

Van Strien, T., Frijters, J. E. R., Bergers, G. P. A., \& Defares, P. B. (1986). The Dutch Eating Behaviour Questionnaire (DEBQ) for assessment of restrained, emotional and external eating behaviour. International Journal of Eating Disorders, 5, 295-315.

Van Strien, T. \& Ouwens, M. A. (2003). Counterregulation in female obese emotional eaters: Schachter, Goldman, and Gordon's (1968) test of psychosomatic theory revisited. Eating Behaviors, 3, 329-340.

Van Strien, T., Ouwens, M. A., Engel, C., \& de Weerth, C. (2014). Hunger, inhibitory control and distress-induced emotional eating. Appetite, 79, 124-133.

Van Strien, T., Herman, C. P., Anschutz, D., Engels, R. C. M. E. \& de Weerth, C. (2012). 
Moderation of distress-induced eating by emotional eating scores. Appetite, 58, 277284.

Van Strien, T., Cebolla, A., Etchemendy, E., Gutiërez-Maldonado, J., Ferrer-Garcia, M., Botella, C., \& Baños, R. (2013). Emotional eating and food intake after sadness and joy. Appetite, 66, 20-25.

Van Strien, T., Roelofs, K, de Weerth, C. (2013). Cortisol reactivity and distress-induced emotional eating. Psychoneuroendocrinology, 38 (5), 677-684.

Van Strien, T., \& Van de Laar, F. (2008). Intake of energy is best predicted by overeating tendency and consumption of fat is best predicted by dietary restraint. A four-year follow up of patients with newly diagnosed type-2 diabetes. Appetite, 50, 544-547.

Van Strien, T. (1996). On the relationship between dieting and obese and bulimic eating patterns. International Journal of Eating Disorders, 19, 83-92.

Wegner, K. E., Smyth, J. M., Crosby, R. D., Wittrock, D., Wonderlich, S. A., \& Mitchell, J. E. (2002). An evaluation of the relationship between mood and binge eating in the natural environment using ecological momentary assessment. International Journal of eating Disorders, 32, 352-361. Doi:10:10.1002/eat.10086

Wallis, D. J. \& Hetherington, M. M. (2004). Stress and eating. The effects of ego-threat and cognitive demand on food intake in restrained and emotional eaters. Appetite, 43, 3946.

Wansink, B., Cheney, M. M., \& Chan, N. (2003). Exploring comfort food preferences across age and gender. Physiology \& Behavior, 79, 739-747.

Watson, D., Clark, L. A. \& Tellegen, A. (1988). Development and validation of Brief Measures of Positive and Negative Affect: The PANAS Scales. Journal of Personality and Social Psychology, 54, 1063-1070. 
900 Whisman, M. A., \& McClelland, G. H. (2005). Designing, testing and interpreting 19, 111-120. 
Table 1. Pearson correlations for associations between variables in Study 1 and descriptive statistics $(n=29)$

\begin{tabular}{|c|c|c|c|c|c|c|c|c|}
\hline & $\begin{array}{l}\text { Decrease in } \\
\text { sadness }^{\mathrm{a}}\end{array}$ & $\begin{array}{l}\text { Increase in } \\
\text { happiness }^{\mathrm{a}}\end{array}$ & $\begin{array}{l}\text { Energy intake } \\
\text { (kcal) }\end{array}$ & $\begin{array}{l}\text { Eating } \\
\text { satisfaction }\end{array}$ & Pre-sad & Pre- joy & Guilty & BMI \\
\hline Increase in happiness ${ }^{a}$ & - & & & & & & & \\
\hline Energy intake & $-0.42 *$ & 0.20 & & & & & & \\
\hline Eating satisfaction & $-0.65 * *$ & $0.58^{*}$ & $0.50^{* *}$ & & & & & \\
\hline Baseline sad & $0.50 *$ & -0.26 & -0.12 & -0.33 & & & & \\
\hline Baseline happy & -0.25 & $0.48^{*}$ & 0.15 & 0.06 & -0.22 & & & \\
\hline Guilty & 0.38 & -0.37 & 0.23 & -0.18 & 0.36 & -0.29 & & \\
\hline BMI & -0.15 & -0.18 & -0.14 & 0.19 & -0.27 & -0.04 & -0.06 & \\
\hline mean & - & - & 157.41 & 4.52 & 1.55 & 5.14 & 1.69 & 22.32 \\
\hline SD & - & - & 110.25 & 1.64 & 0.87 & 1.16 & 1.23 & 3.35 \\
\hline
\end{tabular}

$\bar{*} \mathrm{p}<.05 ;{ }^{* *} \mathrm{p}<.01 ;{ }^{\text {a }}$ partial correlations (T3 sadness, or happiness, respectively controlling for T2 sadness, or T2 happiness); decrease in sadness is reflected by a negative score; increase in happiness is reflected by a positive score. 
Table 2. Pearson correlations for associations between variables in Study 2 and descriptive statistics $(n=74)$

\begin{tabular}{|c|c|c|c|c|c|c|c|c|}
\hline & $\begin{array}{l}\mathrm{AUCg} \\
\text { stress }\end{array}$ & $\begin{array}{l}\text { Total } \\
\text { Energy } \\
(\mathrm{kcal})\end{array}$ & $\begin{array}{l}\text { "Lekker" } \\
\text { (tastiness) }\end{array}$ & $\begin{array}{l}\text { Emotional } \\
\text { eating }\end{array}$ & $\begin{array}{l}\text { Negative } \\
\text { Affect - } \\
\text { control }\end{array}$ & $\begin{array}{l}\text { Hunger } \\
\text { control }\end{array}$ & $\begin{array}{l}\text { Hunger } \\
\text { stress }\end{array}$ & $\begin{array}{l}\text { Snack } \\
\text { Energy } \\
(\mathrm{kcal})\end{array}$ \\
\hline Total energy (kcal) & 0.15 & & & & & & & \\
\hline "Lekker" (tastiness) & 0.13 & -0.20 & & & & & & \\
\hline Emotional eating & 0.18 & 0.14 & 0.09 & & & & & \\
\hline Negative Affect-control & $-0.31 * *$ & -0.02 & 0.06 & -0.01 & & & & \\
\hline Hunger control & 0.18 & -0.10 & 0.03 & 0.06 & 0.01 & & & \\
\hline Hunger stress & $0.31^{*}$ & $0.30 * *$ & 0.16 & 0.17 & 0.05 & $0.42 * *$ & & \\
\hline Snack energy (kcal) & 0.15 & 0.99 & -0.22 & 0.14 & -0.04 & -0.08 & $0.27 *$ & \\
\hline Mean & 5.05 & 44.41 & 3.68 & 2.84 & -0.11 & 5.77 & 4.82 & 40.37 \\
\hline $\mathrm{SD}$ & 1.98 & 187.04 & 0.59 & 1.11 & 0.24 & 2.35 & 2.37 & 180.17 \\
\hline
\end{tabular}

$* \mathrm{p}<.05 ; * * \mathrm{p}<.01$ 
Figure Captions.

Figure 1. Statistical pathway diagram of the mediation analysis of eating satisfaction (M) between food intake (X) and decrease in sadness (Y) in Study $1(n=29)$. Unstandardized beta coefficients (with bias-corrected and accelerated bootstrap 95\% confidence intervals) are shown on the arrows. The coefficients are negative because greater food intake, or eating satisfaction, are associated with a larger decline in sadness. For details of these and additional pathway tests, see 2.3.3.

Figure 2. Statistical pathway diagram of the mediation analysis of eating satisfaction (M) between food intake (X) and increase in happiness (Y) in Study $1(n=29)$. Unstandardized beta coefficients (with bias-corrected and accelerated bootstrap 95\% confidence intervals) are shown on the arrows. For details of these and additional pathway tests, see 2.3.3.

Figure 3. The values for negative mood in the control and the stress condition upon arrival (T1), immediately after the task (T2), after the message of having to wait for the jury's judgement on the performance (in the stress condition) (T3), and during the food intake (T4).

Figure 4. Statistical pathway diagram of the moderated mediation analysis of emotional eating (W) as moderator variable of the mediation model of tastiness (M) between food intake (X) and negative mood reactivity during distress (AUCg_stress; Y) in Study 2 ( $n=74)$. Unstandardized beta coefficients (with bias-corrected and accelerated bootstrap 95\% confidence intervals) are shown on the arrows. For details of these and additional pathway tests, see 3.3.4. 


\section{Figure 1.}

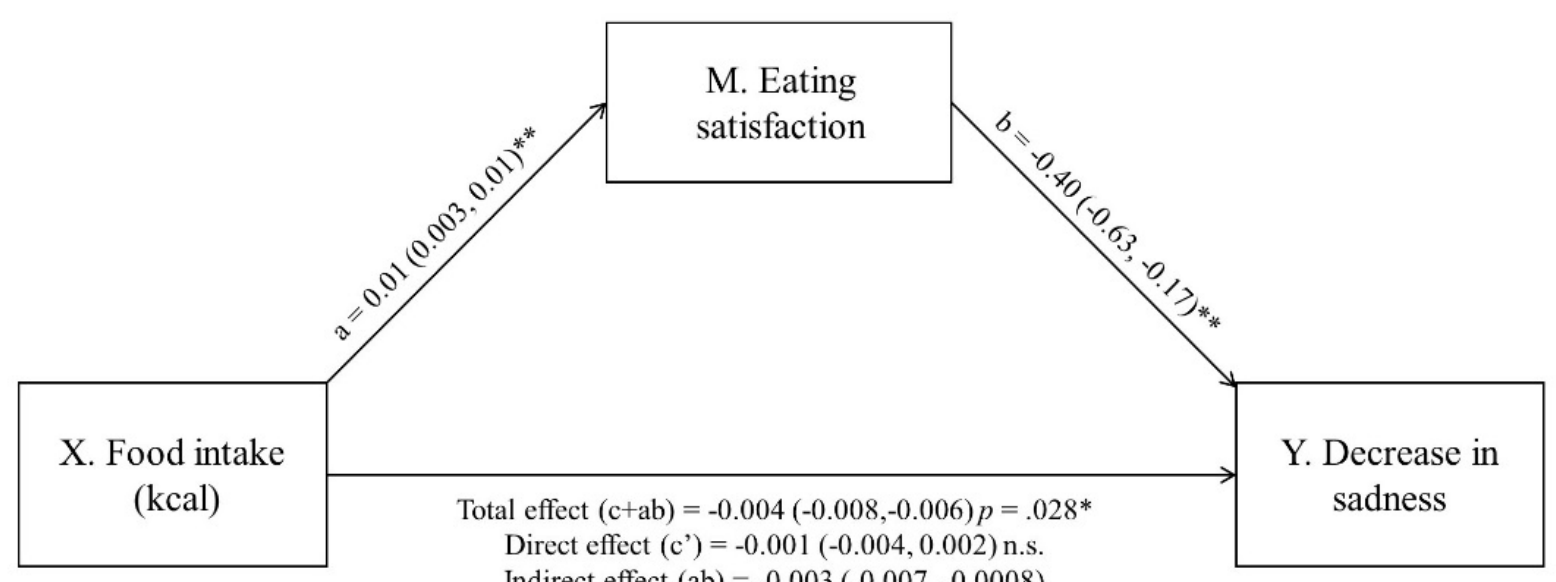

\section{sadness}

Direct effect $\left(c^{\prime}\right)=-0.001(-0.004,0.002)$ n.s.

Indirect effect $(\mathrm{ab})=-0.003(-0.007,-0.0008)$ 
Figure 2. 


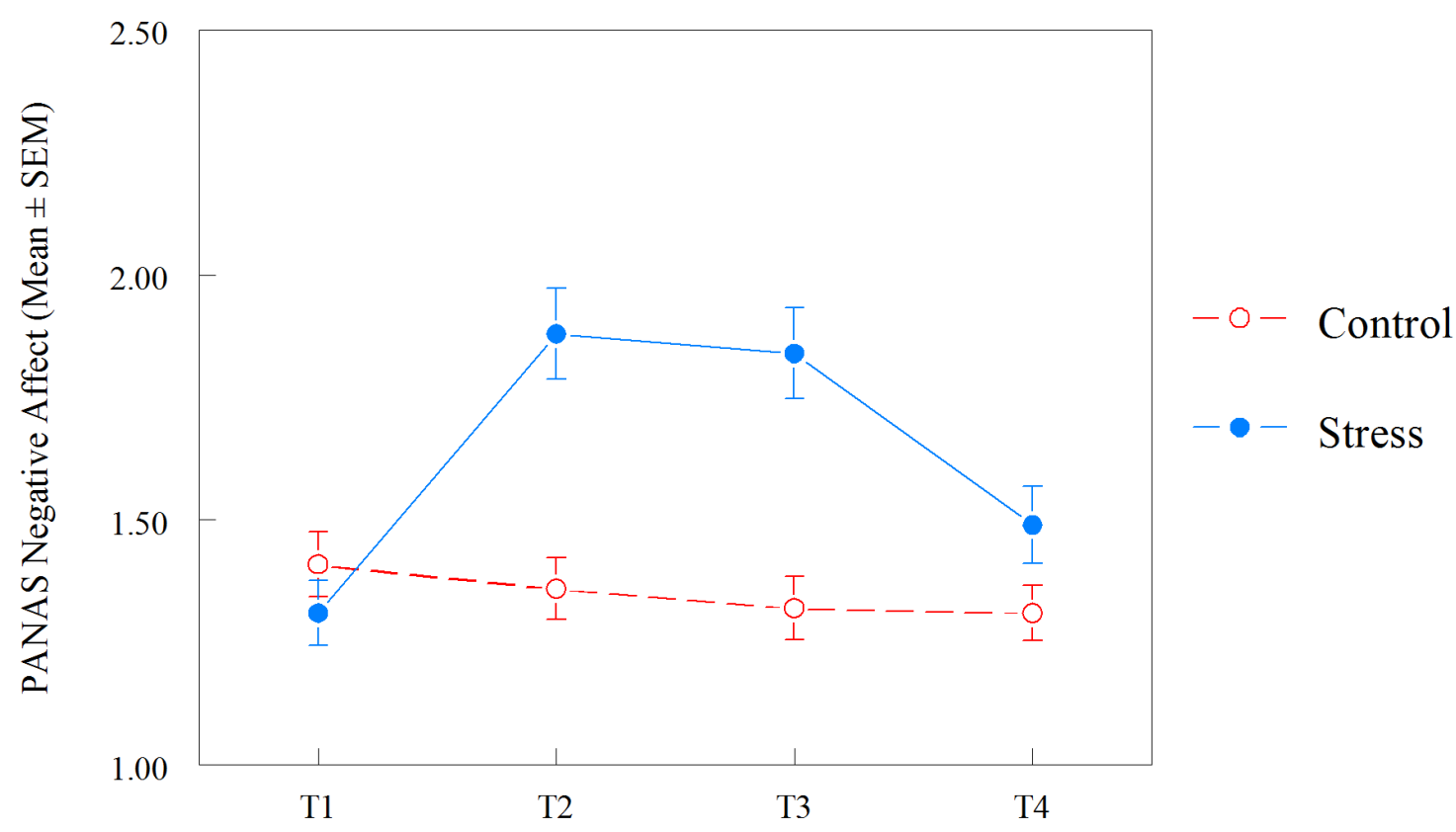

Figure 3. 


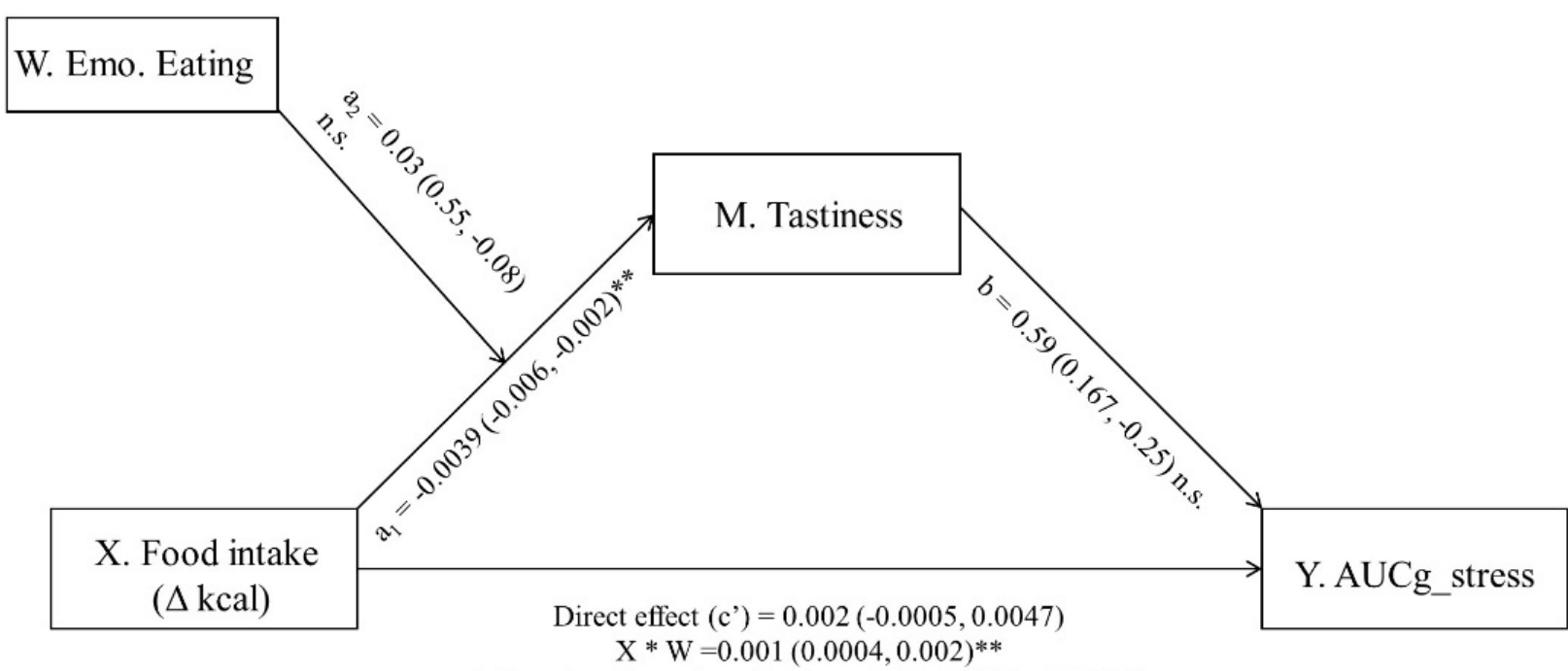

Index of moderated mediation $=.0007(0.0001,0.00234)$

Figure 4. 


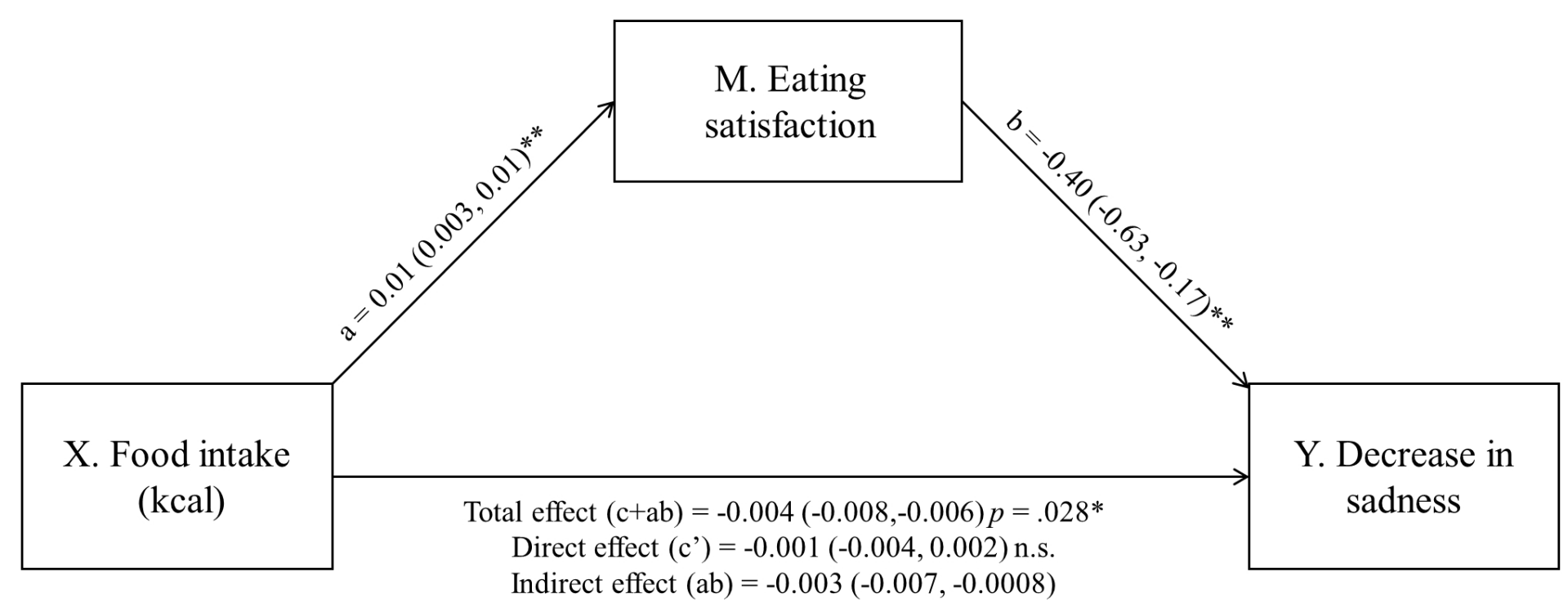




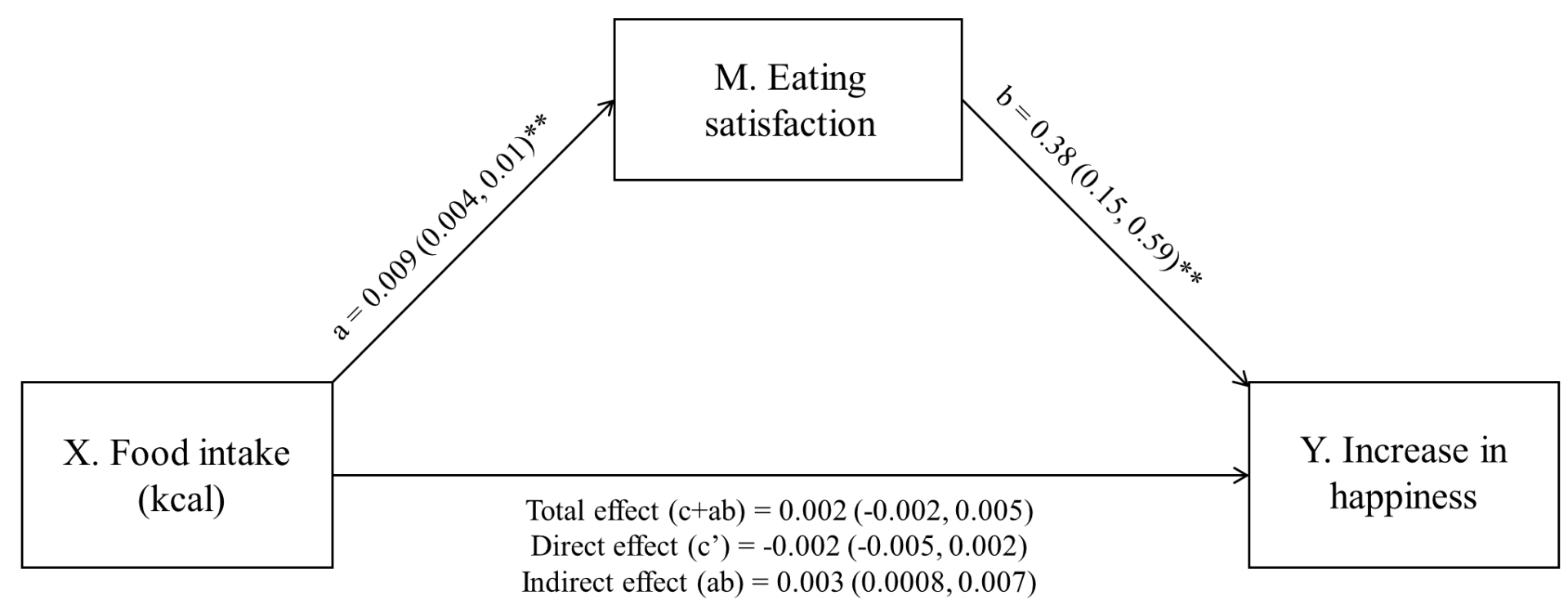




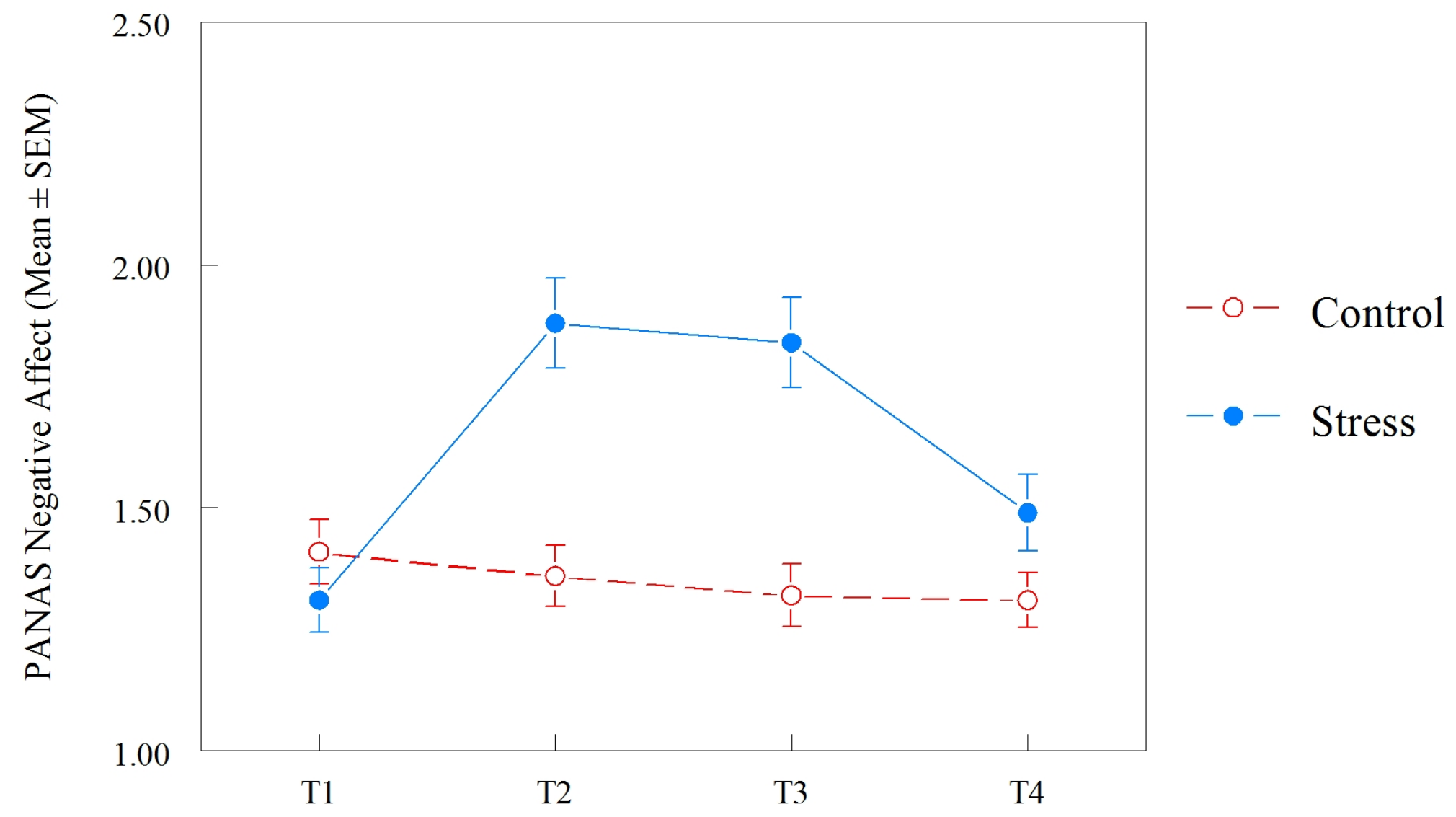




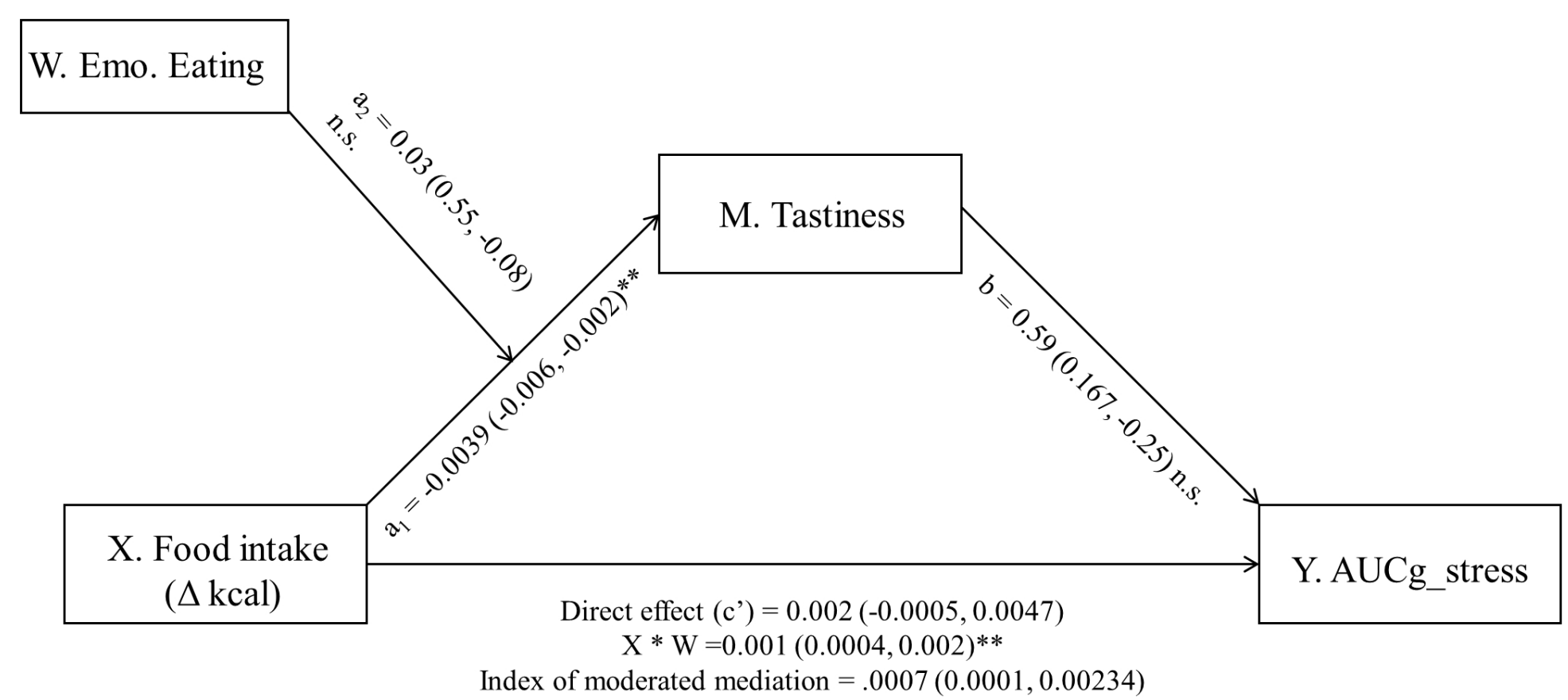

